\title{
Estado nutricional e produção de laranjeira 'Pêra' em função da vegetação intercalar e cobertura morta
}

\author{
Horst Bremer Neto(1), Ricardo Victoria Filho(1), Francisco de Assis Alves Mourão Filho(1), \\ Gilberto Mendonça de Menezes ${ }^{(2)}$ e Émerson Canali ${ }^{(2)}$
}

\begin{abstract}
(1)Escola Superior de Agricultura Luiz de Queiroz, Caixa Postal 9, CEP 13418-900 Piracicaba, SP, Brasil. E-mail: hbremer@esalq.usp.br, rvictori@esalq.usp.br, famourao@esalq.usp.br (2)Branco Peres Citrus, Rua Santa Catarina, no 37, CEP $14900-000$ Itápolis, SP. E-mail: gmenezes@brancoperes.com.br, emersoncanali@ig.com.br
\end{abstract}

\begin{abstract}
Resumo - O objetivo deste trabalho foi avaliar os efeitos da cobertura morta e da vegetação intercalar composta por gramíneas e leguminosas perenes nas propriedades químicas do solo e no estado nutricional de plantas de laranjeira 'Pêra' (Citrus sinensis (L.) Osbeck) enxertada em limoeiro 'Cravo' (Citrus limonia Osbeck). Os tratamentos testados foram: T1, Brachiaria ruziziensis R. Germ. \& Evrard na entrelinha sem cobertura morta na linha; T2, B. ruziziensis na entrelinha e cobertura morta na linha; T3, B. ruziziensis consorciada com amendoim forrageiro (Arachis pintoi Krap. \& Greg) na entrelinha e cobertura morta na linha; T4, B. ruziziensis e estilosantes (Stylosanthes capitata, S. macrocephala e S. guianensis) na entrelinha e cobertura morta na linha; T5, capimmarmelada (Brachiaria plantaginea (Link) Hitch.) na entrelinha e cobertura morta na linha; T6, amendoim forrageiro na entrelinha e cobertura morta na linha; T7, estilosantes na entrelinha e cobertura morta na linha. A leguminosa estilosantes proporcionou aumento da concentração foliar de $\mathrm{N}$ em relação à vegetação intercalar composta por B. ruziziensis. A cobertura morta não reduziu a disponibilidade de $\mathrm{N}$ para as plantas cítricas. Verificou-se correlação entre a densidade do sistema radicular na camada superficial do solo com a concentração foliar de P e produção de frutos.
\end{abstract}

Termos para indexação: Arachis pintoi, Brachiaria ruziziensis, Citrus, Stylosanthes, adubação verde.

\section{Nutritional status and production of 'Pêra' sweet orange related to cover crops and mulch}

\begin{abstract}
The objective of this work was to evaluate the effects of cover crops composed of grass and perennial leguminous in the orchard inter-rows and mulch on the rows, on soil chemical characteristics and nutritional status of Citrus sinensis (L.) Osbeck cv. Pêra sweet orange budded on 'Rangpur' lime (Citrus limonia Osbeck). The treatments were: T1, Cover crop of Brachiaria ruziziensis R. Germ. \& Evrard, without mulch on the row; $\mathrm{T} 2$, B. ruziziensis and mulch on the row; T3, B. ruziziensis and Arachis pintoi and mulch on the row; $\mathrm{T} 4$, B. ruziziensis and stylosanthes and mulch on the row; T5, Brachiaria plantaginea and mulch on the row; T6, Arachis pintoi and mulch on the row; T7, stylosanthes and mulchon the row. Stylosanthes increased N leaf content compared to $B$. ruziziensis. Grass mulch had no significant effect on $\mathrm{N}$ leaf content. There was significant interaction between root density into superficial soil layer, $\mathrm{P}$ leaf content and yield.
\end{abstract}

Index terms: Arachis pintoi, Brachiaria ruziziensis, Citrus, Stylosanthes, green manure.

\section{Introdução}

A maioria dos solos cultivados com plantas cítricas no Sudeste do Brasil apresenta acidez elevada, alumínio em níveis tóxicos, baixa capacidade de retenção de cátions e baixos teores de bases (Melarato, 1998). Sob essas condições, a adubação verde é uma técnica recomendada, pois pode promover benefícios como aumento da capacidade de troca de cátions, das concentrações de $\mathrm{Ca}, \mathrm{Mg}$ e matéria orgânica e redução dos teores de $\mathrm{H}+\mathrm{Al}$ e fixação biológica do $\mathrm{N}_{2}$ quando são utilizadas leguminosas (Pavan et al., 1986; Menegucci et al., 1995; Carvalho et al., 1998; Alcântra et al., 2000; Neves \& Dechen, 2001; Silva et al., 2002; Perin et al., 2004).

A maioria dos estudos sobre sistemas de manejo de solo para a citricultura tem envolvido espécies anuais (Neves \& Dechen, 2001), no entanto, trabalhos de pesquisa com gramíneas e leguminosas perenes demonstraram algumas vantagens do uso destas 
espécies. Fidalski \& Stenzel (2006) verificaram em pomar de laranjeira 'Folha Murcha' enxertada sobre o limoeiro 'Cravo' que a vegetação intercalar composta predominantemente pela gramínea Paspalum notatum proporcionou menor acidez e maior disponibilidade de $\mathrm{P}$ em relação à vegetação intercalar composta por Arachis pintoi. Por sua vez, laranjeiras consorciadas com a leguminosa apresentaram maior concentração foliar de N. Além disso, o manejo da gramínea $P$. notatum nas entrelinhas proporcionou melhores relações hídricas e metabólicas em laranjeira 'Pêra' enxertada sobre o limoeiro 'Cravo' em relação à cobertura permanente composta por A. pintoi e ao manejo com baixa cobertura vegetal, no entanto a produção de frutos foi a mesma para os diferentes manejos (Fidalski et al., 2006).

O manejo dos adubos verdes deve deixar a fitomassa sobre o solo e pode ser realizado com roçadeira, rolofaca, trituradores ou implementos que tombam a fitomassa sobre o solo (Donizeti Carlos et al., 2006). Recentemente, foram desenvolvidas roçadeiras enleiradoras lateral (REL), denominadas comercialmente de ecológicas, capazes de cortar a vegetação intercalar e distribuí-la simultaneamente sobre a linha da cultura, formando uma camada de cobertura morta sob a copa das plantas cítricas (Corá et al., 2005).

Pesquisas sobre o manejo de leguminosas anuais com REL foram conduzidas em pomares cítricos do Estado de São Paulo (Matheis \& Victoria Filho, 2005; Ragozo et al., 2006). No entanto, não foram encontrados estudos sobre gramíneas e leguminosas perenes submetidas ao manejo com REL e seu efeito sobre a fertilidade do solo e no estado nutricional de citros. A distribuição de cobertura morta pode alterar o balanço entre mineralização e imobilização do $\mathrm{N}$ do solo, reduzindo sua disponibilidade para as laranjeiras e exigindo adubações complementares desse nutriente. Em trabalhos anteriores, foi constatada redução da concentração foliar de $\mathrm{N}$ ao longo de um ciclo completo de laranjeira mantida com cobertura morta proveniente de gramíneas (Gallo \& Rodriguez, 1960). Por sua vez, a cobertura morta pode favorecer o crescimento do sistema radicular nas camadas superficiais do solo (Faber et al., 2001), o que favorece a absorção de nutrientes como o $\mathrm{P}$, que devido à baixa mobilidade, acumula-se nas camadas superficiais (Quaggio et al., 2005).

O objetivo deste trabalho foi avaliar os efeitos da associação da vegetação intercalar, composta por gramíneas e leguminosas perenes, e da cobertura morta proveniente da vegetação intercalar, nas propriedades químicas do solo, na densidade do sistema radicular, no estado nutricional e na produção de laranjeira 'Pêra' sobre limoeiro 'Cravo'.

\section{Material e Métodos}

O experimento foi instalado em janeiro de 2004, no Município de Lucianópolis, SP, em área de produção comercial de laranjeira 'Pêra' (Citrus sinensis (L.) Osbeck) enxertada sobre limoeiro 'Cravo' (Citrus limonia Osbeck), implantada em outubro de 2002, em espaçamento de 7,0x3,5 m. As propriedades químicas do solo na camada de $0-20 \mathrm{~cm}$ de profundidade antes da instalação do experimento foram: $\mathrm{pH}\left(\mathrm{CaCl}_{2}\right), 5,2$; MO, $12 \mathrm{~g} \mathrm{dm}^{-3}$; $\mathrm{P}, 8 \mathrm{mg} \mathrm{dm}^{-3}$; K, 0,7 $\mathrm{mmol}_{\mathrm{c}} \mathrm{dm}^{-3}$; $\mathrm{Ca}$, $14 \mathrm{mmol}_{\mathrm{c}} \mathrm{dm}^{-3} ; \mathrm{Mg}, 11 \mathrm{mmol}_{\mathrm{c}} \mathrm{dm}^{-3} ; \mathrm{H}+\mathrm{Al}, 18 \mathrm{mmol}_{\mathrm{c}} \mathrm{dm}^{-3}$; $\mathrm{T}, 43,7 \mathrm{mmol}_{\mathrm{c}} \mathrm{dm}^{-3} ; \mathrm{V}, 58,8 \%$. A adubação mineral foi realizada igualmente em todos os tratamentos com $\mathrm{N}-\mathrm{P}_{2} \mathrm{O}_{5}-\mathrm{K}_{2} \mathrm{O}$ nas seguintes quantidades $\left(\mathrm{kg} \mathrm{ha}^{-1} \mathrm{safra}^{-1}\right)$ : safra 2003/2004, 74-16-75; safra 2004/2005, 132-31-83; safra 2005/2006, 114-62-72. As adubações foliares forneceram anualmente $11 \mathrm{~kg} \mathrm{ha}^{-1}$ de $\mathrm{N}, 5 \mathrm{~kg} \mathrm{ha}^{-1}$ de Zn e $3 \mathrm{~kg} \mathrm{ha}^{-1}$ de Mn. Aplicaram-se 2.090 e $1.061 \mathrm{~kg} \mathrm{ha}^{-1}$ de calcário dolomítico, na superfície do solo, nas safras 2003/2004 e 2004/2005, respectivamente.

O delineamento estatístico utilizado foi o de blocos ao acaso, com sete tratamentos e quatro repetições. As parcelas foram compostas por quatro linhas contendo cinco laranjeiras, sendo as seis plantas centrais consideradas úteis. Os tratamentos testados foram: T1, Brachiaria ruziziensis R. Germ. \& Evrard na entrelinha sem cobertura morta na linha; T2, B. ruziziensis na entrelinha e cobertura morta na linha; T3, B. ruziziensis consorciada com amendoim forrageiro (Arachis pintoi) na entrelinha e cobertura morta na linha; T4, B. ruziziensis e estilosantes [Stylosanthes capitata Vogel (60\%), S. macrocephala M.B. Ferreira \& S. Costa (25\%) e S. guianensis (Aublet) Sw. (15\%)] na entrelinha e cobertura morta na linha; T5, capim-marmelada (Brachiaria plantaginea (Link) Hitch.) na entrelinha e cobertura morta na linha; T6, amendoim forrageiro na entrelinha e cobertura morta na linha; T7, estilosantes na entrelinha e cobertura morta na linha. A cobertura morta foi obtida a partir do manejo dos adubos verdes com roçadeira enleiradora lateral (marca Kamaq modelo Samuraimac), que corta a vegetação intercalar e a distribui simultaneamente sobre as linhas da cultura. A vegetação intercalar do tratamento 1 
foi manejada com roçadeira convencional nos mesmos momentos dos demais tratamentos, de forma que a fitomassa roçada permanecesse sobre as entrelinhas.

O preparo do solo das entrelinhas para a semeadura dos adubos verdes consistiu da seguinte seqüência de operações: aplicação de $60 \mathrm{~kg} \mathrm{ha}^{-1}$ de $\mathrm{P}_{2} \mathrm{O}_{5}$, gradagem a aproximadamente $20 \mathrm{~cm}$ de profundidade, gradagem leve, semeadura a lanço dos adubos verdes, gradagem leve e rolo compactador para a cobertura das sementes. A taxa de semeadura foi de $5 \mathrm{~kg} \mathrm{ha}^{-1}$ de sementes puras viáveis (SPV) de B. ruziziensis e capim-marmelada, $2 \mathrm{~kg} \mathrm{ha}^{-1}$ de SPV de estilosantes e $12,5 \mathrm{~kg} \mathrm{ha}^{-1}$ de SPV de amendoim forrageiro. Nos consórcios, a taxa de semeadura dessas leguminosas foi reduzida em $30 \%$.

As amostras para avaliação da massa de matéria seca da cobertura morta distribuída pela REL sobre a linha de plantio foram obtidas com o auxílio de um quadro metálico com dimensões de $0,25 \times 0,50 \mathrm{~m}$, lançado aleatoriamente seis vezes sobre as linhas de laranjeiras da parcela. Após a coleta, as amostras foram secadas em estufa a $70^{\circ} \mathrm{C}$ até massa constante.

A coleta de amostras de solo na linha da cultura foi realizada em abril de 2006 nas camadas de 0-20 e 20-40 cm de profundidade. Foram feitas as seguintes determinações: $\mathrm{pH}$ (potenciometria), MO (colorimetria), $\mathrm{P}$ (extração com resina trocadora de íons e determinação por colorimetria), $\mathrm{K}$ (resina trocadora de íons e determinação por fotometria de chama), $\mathrm{Ca}$ e $\mathrm{Mg}$ (resina trocadora de íons e determinação por absorção atômica), $\mathrm{H}+\mathrm{Al}$ (potenciometria), SB, T e V. Simultaneamente à coleta de solo, foram coletadas amostras de folha das laranjeiras (quarta folha a partir do fruto), geradas na primavera, de ramos frutíferos, duas de cada quadrante, na altura mediana da planta, conforme método descrito por Malavolta (1992). Nesse material, foram determinados N (destilação pelo método Kjeldahl), P (digestão nítricoperclórica com determinação por colorimetria), $\mathrm{K}, \mathrm{Ca}$, $\mathrm{Mg}, \mathrm{Cu}, \mathrm{Fe}, \mathrm{Mn}$ e Zn (digestão nítrico-perclórica com determinação por espectrofotometria de absorção atômica), B (Azometrina - H, com determinação por colorimetria).

A avaliação da densidade do sistema radicular foi realizada em outubro de 2006. As amostras de solo foram retiradas de todas as plantas úteis nas camadas de 0-10 e 10-20 $\mathrm{cm}$ de profundidade, com auxílio de sonda de PVC com 7,5 cm de diâmetro a uma distância de $1,10 \mathrm{~m}$ do tronco no sentido da entrelinha, local coincidente com a projeção da copa das laranjeiras. Após a coleta, as raízes foram separadas do solo com auxílio de peneira com malha de $3 \mathrm{~mm}$, lavadas e secadas em estufa a temperatura de $70^{\circ} \mathrm{C}$ até massa constante. Determinou-se apenas a massa das raízes com $1 \mathrm{~mm}$ ou menos de diâmetro, consideradas as mais importantes na absorção de água e nutrientes (Medina et al., 2005).

A produção de frutos foi avaliada nas safras 2005/ 2006 e 2006/2007. Foram colhidos os frutos das seis plantas centrais de cada parcela e a massa total foi determinada com auxílio de balança digital com capacidade para $150 \mathrm{~kg}$.

Os dados foram submetidos à análise de variância e as médias comparadas pelo teste de Tukey, a 5\% de probabilidade. Análises de regressão linear foram realizadas, tendo como variável independente a densidade do sistema radicular, utilizando o teste $\mathrm{F}$, a $5 \%$ de probabilidade.

\section{Resultados e Discussão}

Embora tivessem sido verificadas diferenças na quantidade de cobertura morta depositada sobre o solo das linhas das laranjeiras (Tabela 1), o aporte de nutrientes promovido pela cobertura morta foi insuficiente para promover alterações significativas nas propriedades químicas do solo até o momento da avaliação (Tabela 2). O curto tempo de duração do experimento pode ser uma das razões para que alterações significativas nas propriedades químicas do solo não ocorressem, pois no trabalho de Neves \& Dechen (2001), a cobertura vegetal proporcionou incremento do teor de matéria orgânica após dez anos da implantação dos adubos verdes. Além disso, o amendoim forrageiro e o estilosantes produziram

Tabela 1. Cobertura morta ( $\mathrm{g}$ de massa seca por $\mathrm{m}^{2}$ ) distribuída sobre a linha de laranjeira 'Pêra', pelo manejo de adubos verdes com roçadeira, de 2004 a 2006.

\begin{tabular}{cccccr}
\hline Tratamento $^{(1)}$ & \multicolumn{5}{c}{ Cobertura morta } \\
\cline { 2 - 6 } & Jun./2004 & Jan./2005 & Jun./2005 & Jan./2006 & Total \\
\hline T1 & 0 & 0 & 0 & 0 & 0 \\
T2 & 402 & 565 & 258 & 367 & 1.591 \\
T3 & 313 & 620 & 262 & 315 & 1.511 \\
T4 & 289 & 654 & 255 & 352 & 1.550 \\
T5 & 370 & 476 & 21 & 20 & 887 \\
T6 & 0 & 0 & 111 & 123 & 235 \\
T7 & 0 & 653 & 146 & 200 & 1.000 \\
\hline
\end{tabular}

${ }^{(1)} \mathrm{T} 1$, Brachiaria ruziziensis (B.r.) na entrelinha sem cobertura morta (CM) na linha; T2, B.r. na entrelinha e CM na linha; T3, B.r. consorciada com amendoim forrageiro na entrelinha e CM na linha; T4, B.r. e estilosantes na entrelinha e CM na linha; T5, capim-marmelada na entrelinha e CM na linha; T6, amendoim forrageiro na entrelinha e CM na linha; T7, estilosantes na entrelinha e CM na linha. 
fitomassa suficiente para a roçagem aos 530 e 343 dias após a semeadura, respectivamente, e, portanto, as linhas das laranjeiras permaneceram durante o período anterior sem cobertura morta. A contribuição das leguminosas amendoim forrageiro e estilosantes para a composição da biomassa total produzida nos consórcios com B. ruziziensis (T3 e T4) foi de 5 e $15 \%$, respectivamente. Contudo, o estabelecimento das leguminosas em consórcio com B. ruziziensis não ocorreu efetivamente, visto que, em consórcio com gramíneas, a biomassa da leguminosa deve representar pelo menos $30 \%$ da biomassa total (Cadish et al., 1994).

As concentrações foliares de $\mathrm{K}, \mathrm{Ca}, \mathrm{Mg}, \mathrm{B}, \mathrm{Mn}$ e $\mathrm{Zn}$ não foram afetadas, indicando que as laranjeiras absorveram quantidades similares desses nutrientes em todos os tratamentos. Por sua vez, os teores de $\mathrm{N}, \mathrm{P}$ e $\mathrm{Cu}$ sofreram influência dos tratamentos (Tabela 3).

Tabela 2. Propriedades químicas do solo da linha de pomar de laranjeira 'Pêra', nas camadas de 0-20 e 20-40 cm de profundidade, de acordo com o sistema de manejo do solo, em abril 2006.

\begin{tabular}{cccccccccc}
\hline Tratamento $^{(1)}$ & $\begin{array}{c}\mathrm{pH} \\
\left(\mathrm{CaCl}_{2}\right)\end{array}$ & $\begin{array}{c}\mathrm{MO} \\
\left(\mathrm{g} \mathrm{dm}^{-3}\right)\end{array}$ & $\begin{array}{c}\mathrm{P} \\
\left(\mathrm{mg} \mathrm{dm}^{-3}\right)\end{array}$ & $\mathrm{K}$ & $\mathrm{Ca}$ & $\mathrm{Mg}$ & $\begin{array}{c}\mathrm{H}+\mathrm{Al} \\
\mathrm{T}\end{array}$ & $\begin{array}{c}\mathrm{T} \\
(\%)\end{array}$ \\
\hline & & & & $0-20 \mathrm{~cm}$ & & & \\
T1 & 5,2 & 15,5 & 20,3 & 2,0 & 24,3 & 10,8 & 14,3 & 51,3 & 72,3 \\
T2 & 4,9 & 15,0 & 15,0 & 2,4 & 14,3 & 8,3 & 17,0 & 41,9 & 59,0 \\
T3 & 4,9 & 14,8 & 15,5 & 2,4 & 14,5 & 8,3 & 16,5 & 41,7 & 60,3 \\
T4 & 5,1 & 13,5 & 22,0 & 2,3 & 14,0 & 9,0 & 16,0 & 41,3 & 60,3 \\
T5 & 5,0 & 14,0 & 17,5 & 2,0 & 14,3 & 8,3 & 16,8 & 41,2 & 59,0 \\
T6 & 5,0 & 15,5 & 18,3 & 2,2 & 19,0 & 11,5 & 17,5 & 50,2 & 63,8 \\
T7 & 4,9 & 15,5 & 19,0 & 2,0 & 18,5 & 10,8 & 18,0 & 49,3 & 62,5 \\
\hline F & $0,63^{\text {ns }}$ & $2,68^{\text {ns }}$ & $0,43^{\text {ns }}$ & $2,88^{\text {ns }}$ & $2,96^{\text {ns }}$ & $0,71^{\text {ns }}$ & $0,72^{\text {ns }}$ & $3,13^{\text {ns }}$ & $0,97^{\text {ns }}$ \\
CV (\%) & 6,21 & 6,59 & 41,73 & 10,60 & 26,42 & 35,28 & 17,24 & 11,71 & 15,21 \\
\hline & & & & $20-40 \mathrm{~cm}$ & & & & \\
T1 & 5,0 & 11,8 & 7,8 & 1,0 & 16,3 & 12,0 & 16,5 & 45,8 & 63,0 \\
T2 & 4,6 & 12,8 & 7,3 & 1,0 & 13,5 & 10,3 & 19,3 & 44,0 & 55,0 \\
T3 & 4,5 & 11,8 & 5,5 & 1,0 & 11,3 & 8,0 & 19,0 & 39,2 & 50,0 \\
T4 & 4,8 & 11,5 & 9,3 & 1,2 & 13,3 & 10,0 & 16,5 & 40,9 & 58,8 \\
T5 & 4,8 & 11,8 & 6,0 & 0,7 & 9,8 & 7,3 & 17,5 & 35,2 & 49,8 \\
T6 & 4,7 & 12,8 & 10,0 & 0,8 & 11,5 & 7,5 & 17,3 & 37,1 & 52,5 \\
T7 & 4,7 & 12,0 & 8,3 & 0,8 & 11,8 & 7,8 & 17,0 & 37,3 & 53,3 \\
\hline F & $0,56^{\text {ns }}$ & $1,44^{\text {ns }}$ & $1,13^{\text {ns }}$ & $1,14^{\text {ns }}$ & $0,93^{\text {ns }}$ & $1,56^{\text {ns }}$ & $0,40^{\text {ns }}$ & $2,23^{\text {ns }}$ & $0,61^{\text {ns }}$ \\
CV (\%) & 9,36 & 7,04 & 39,66 & 30,65 & 34,76 & 32,14 & 20,25 & 12,89 & 22,48 \\
\hline
\end{tabular}

${ }^{(1)}$ T1, Brachiaria ruziziensis (B.r.) na entrelinha sem cobertura morta (CM) na linha; T2, B.r. na entrelinha e CM na linha; T3, B.r. consorciada com amendoim forrageiro na entrelinha e CM na linha; T4, B.r. e estilosantes na entrelinha e CM na linha; T5, capim-marmelada na entrelinha

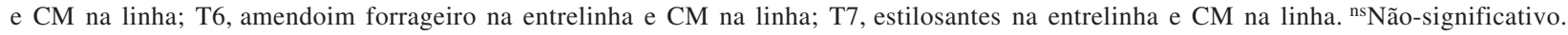

Tabela 3. Composição mineral de macronutrientes $\left(\mathrm{g} \mathrm{kg}^{-1}\right)$ e de micronutrientes $\left(\mathrm{mg} \mathrm{kg}^{-1}\right)$ das folhas de laranjeira 'Pêra', de acordo com o sistema de manejo do solo, em abril $2006^{(1)}$.

\begin{tabular}{cllllllllrr}
\hline Tratamento $^{(2)}$ & $\mathrm{N}$ & $\mathrm{P}$ & $\mathrm{K}$ & $\mathrm{Ca}$ & $\mathrm{Mg}$ & $\mathrm{B}$ & $\mathrm{Cu}$ & $\mathrm{Fe}$ & $\mathrm{Mn}$ & $\mathrm{Zn}$ \\
\hline T1 & $20,10 \mathrm{~b}$ & $1,30 \mathrm{~b}$ & 11,16 & 37,93 & 1,75 & 59,41 & $64,05 \mathrm{ab}$ & 91,63 & 90,45 & 107,10 \\
T2 & $20,13 \mathrm{~b}$ & $1,42 \mathrm{ab}$ & 12,05 & 36,58 & 1,53 & 52,41 & $50,90 \mathrm{~b}$ & 83,40 & 85,38 & 94,30 \\
T3 & $21,00 \mathrm{ab}$ & $1,48 \mathrm{ab}$ & 15,05 & 35,19 & 1,65 & 56,82 & $101,25 \mathrm{a}$ & 95,53 & 96,15 & 111,73 \\
T4 & $20,90 \mathrm{ab}$ & $1,61 \mathrm{a}$ & 13,52 & 37,14 & 2,08 & 52,77 & $100,58 \mathrm{a}$ & 97,15 & 94,78 & 109,70 \\
T5 & $21,28 \mathrm{ab}$ & $1,49 \mathrm{ab}$ & 12,94 & 37,43 & 2,00 & 62,26 & $45,15 \mathrm{~b}$ & 90,23 & 82,28 & 87,88 \\
T6 & $21,28 \mathrm{ab}$ & $1,42 \mathrm{ab}$ & 13,52 & 36,71 & 1,93 & 61,99 & $55,73 \mathrm{~b}$ & 93,20 & 95,70 & 107,80 \\
T7 & $22,68 \mathrm{a}$ & $1,40 \mathrm{ab}$ & 13,58 & 36,33 & 1,80 & 58,65 & $41,83 \mathrm{~b}$ & 91,53 & 82,90 & 85,28 \\
\hline F & $3,34^{*}$ & $2,12^{*}$ & $1,98^{\text {ns }}$ & $0,76^{\text {ns }}$ & $1,44^{\text {ns }}$ & $0,91^{\text {ns }}$ & $9,43^{*}$ & $0,67^{\text {ns }}$ & $1,19^{\text {ns }}$ & $1,96^{\text {ns }}$ \\
CV (\%) & 4,52 & 8,95 & 13,46 & 5,50 & 17,94 & 14,51 & 24,94 & 11,79 & 12,51 & 15,76 \\
\hline
\end{tabular}

${ }^{(1)}$ Médias seguidas pela mesma letra na coluna não diferem entre si pelo teste de Tukey, a 5\% de probabilidade. (2)T1, Brachiaria ruziziensis (B.r.) na entrelinha sem cobertura morta (CM) na linha; T2, B.r. na entrelinha e CM na linha; T3, B.r. consorciada com amendoim forrageiro na entrelinha e CM na linha; T4, B.r. e estilosantes na entrelinha e CM na linha; T5, capim-marmelada na entrelinha e CM na linha; T6, amendoim forrageiro

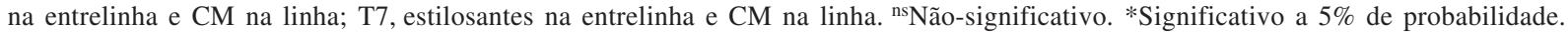


Aos 90 dias após a aplicação da cobertura morta, não foi observada diferença nos teores foliares de $\mathrm{N}$ das laranjeiras cultivadas sem e com cobertura morta de B. ruziziensis (T1 e T2), indicando que a imobilização do $\mathrm{N}$ do solo durante o processo de decomposição da cobertura morta não afetou a disponibilidade de $\mathrm{N}$ para as laranjeiras. Contudo, as laranjeiras destes tratamentos obtiveram menor concentração foliar de $\mathrm{N}$ em relação às laranjeiras, cuja vegetação intercalar foi composta exclusivamente por estilosantes (T7), indicando contribuição da fixação biológica de $\mathrm{N}$, realizada pela leguminosa, para o fornecimento de $\mathrm{N}$ para as laranjeiras. A capacidade dos adubos verdes em fornecer $\mathrm{N}$ proveniente da fixação biológica para os citros foi demonstrada por Silva et al. (2002), que compararam a adubação verde composta por espécies anuais com a adubação convencional, concluindo que os adubos verdes foram capazes de fornecer todo $\mathrm{o} \mathrm{N}$ exigido pela cultura dos citros em formação. As laranjeiras cultivadas com amendoim forrageiro não apresentaram teor de $\mathrm{N}$ superior às cultivadas com $B$. ruziziensis, como observado nas laranjeiras cultivadas com estilosantes, possivelmente pelo maior período de estabelecimento do amendoim forrageiro. Mesmo com a baixa contribuição das leguminosas para a produção total de biomassa dos consórcios (T3 e T4), as concentrações foliares de $\mathrm{N}$ foram intermediárias, situando-se entre as concentrações foliares das laranjeiras consorciadas com estilosantes e o monocultivo de $B$. ruziziensis.

Os teores de $\mathrm{P}$ no solo não diferiram entre os tratamentos. No entanto, laranjeiras consorciadas com a mistura de estilosantes e $B$. ruziziensis com cobertura morta na linha (T4) apresentaram concentração foliar de $\mathrm{P}$ superior às consorciadas com $B$. ruziziensis sem cobertura morta (T1), indicando que as laranjeiras daquele tratamento absorveram maiores quantidades de $\mathrm{P}$.

A densidade do sistema radicular nas camadas superficiais do solo não foi alterada pelos tratamentos, possivelmente pelo curto período em que o experimento foi conduzido (Tabela 4). Entretanto, foi observada correlação positiva entre a concentração foliar de $\mathrm{P}$ e a densidade das raízes na camada de 0-10 cm de solo (Figura 1). Tal correlação explica a maior concentração foliar das laranjeiras do tratamento 4 em relação ao tratamento 1 e ainda indica que aumentos na eficiência da adubação fosfatada podem ser obtidos com o aumento da densidade do sistema radicular nas camadas superficiais do solo, onde o $\mathrm{P}$ encontra-se em maior concentração. Contudo, quando se considera a concentração de $\mathrm{P}$ e a densidade do sistema radicular das laranjeiras cultivadas com amendoim forrageiro e estilosantes, a correlação deixa de ser significativa, visto que, mesmo apresentando menor quantidade de raízes, as laranjeiras cultivadas com esses adubos verdes apresentaram concentração foliar de P similar aos demais tratamentos. Tal resultado pode ser atribuído à maior capacidade das leguminosas em extrair e reciclar $\mathrm{P}$ do solo em relação às gramíneas (Silva et al., 2002; Fidalski \& Stenzel, 2006).

Tabela 4. Densidade das raízes fibrosas $\left(\mathrm{g} 100 \mathrm{~cm}^{-3}\right)$ de laranjeira 'Pêra' sobre limoeiro 'Cravo', nas camadas de 0-10 e 10-20 cm de profundidade, de acordo com o sistema de manejo de solo, em outubro de 2006.

\begin{tabular}{cccc}
\hline Tratamento $^{(1)}$ & \multicolumn{3}{c}{ Densidade das raízes fibrosas } \\
\cline { 2 - 4 } & $0-10 \mathrm{~cm}$ & $10-20 \mathrm{~cm}$ & Total \\
\hline T1 & 0,27 & 0,29 & 0,56 \\
T2 & 0,30 & 0,25 & 0,55 \\
T3 & 0,30 & 0,32 & 0,62 \\
T4 & 0,37 & 0,29 & 0,65 \\
T5 & 0,34 & 0,24 & 0,58 \\
T6 & 0,20 & 0,25 & 0,45 \\
T7 & 0,24 & 0,25 & 0,49 \\
\hline F & $1,24^{\mathrm{ns}}$ & $0,54^{\mathrm{ns}}$ & $0,74^{\mathrm{ns}}$ \\
CV (\%) & 35,72 & 28,82 & 29,45 \\
\hline
\end{tabular}

${ }^{(1)} \mathrm{T} 1$, Brachiaria ruziziensis (B.r.) na entrelinha sem cobertura morta (CM) na linha; T2, B.r. na entrelinha e CM na linha; T3, B.r. consorciada com amendoim forrageiro na entrelinha e $\mathrm{CM}$ na linha; T4, B.r. e estilosantes na entrelinha e CM na linha; T5, capim-marmelada na entrelinha e CM na linha; T6, amendoim forrageiro na entrelinha e CM na linha; T7, estilosantes na entrelinha e CM

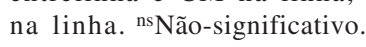

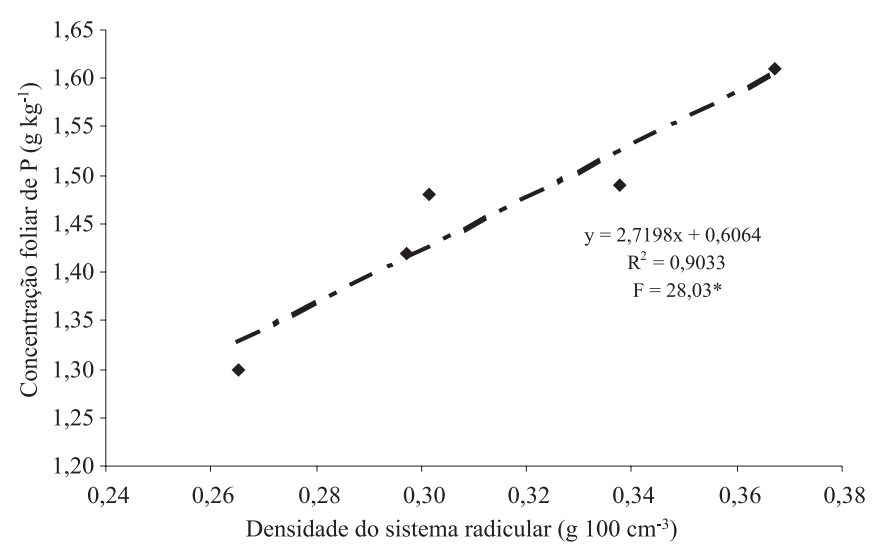

Figura 1. Concentração foliar de $\mathrm{P}$ de laranjeira 'Pêra' enxertada em limoeiro 'Cravo', decorrente da densidade de raízes fibrosas na camada de $0-10 \mathrm{~cm}$ de profundidade. ${ }^{*}$ Significativo pelo teste $\mathrm{F}$, a $5 \%$ de probabilidade. 
As concentrações foliares de $\mathrm{Cu}$ das laranjeiras de todos os tratamentos apresentaram valores muito acima da faixa de interpretação considerada excessiva, que é de $15 \mathrm{mg} \mathrm{kg}^{-1}$ (Quaggio et al., 2005). Pulverizações freqüentes de defensivos agrícolas contendo $\mathrm{Cu}$ possivelmente são a causa das elevadas concentrações deste elemento nas folhas das laranjeiras.

Os tratamentos não afetaram a produção da safra 2005/2006, no entanto, na safra 2006/2007, as laranjeiras cuja vegetação intercalar foi composta pelo consórcio entre $B$. ruziziensis e estilosantes na entrelinha e cobertura morta na linha (T4) tiveram maior produção de frutos em relação às plantas mantidas com vegetação intercalar de amendoim forrageiro (T6) (Tabela 5). Não foram verificadas diferenças na análise química do solo ou no estado nutricional das laranjeiras que pudessem produzir estes resultados. Contudo, verificou-se correlação positiva entre a produção de frutos e a densidade do sistema radicular na camada de $0-10 \mathrm{~cm}$ de solo (Figura 2), indicando que, mesmo diferenças nãosignificativas na quantidade do sistema radicular, como a observada entre os tratamentos 4 e 6 , são suficientes para promover incrementos na produção de frutos. O maior período de estabelecimento do amendoim forrageiro permitiu que o solo, tanto das linhas quanto das entrelinhas, permanecesse exposto aos agentes de degradação, prejudicando o desenvolvimento do sistema

Tabela 5. Produção de frutos (quilograma por planta) de laranjeira 'Pêra' sobre limoeiro 'Cravo', de acordo com o sistema de manejo de solo, de 2005 a $2007^{(1)}$.

\begin{tabular}{cccc}
\hline Tratamento $^{(2)}$ & \multicolumn{3}{c}{ Produção de frutos } \\
\cline { 2 - 4 } & Safra & Safra & Total \\
& $2005 / 2006$ & $2006 / 2007$ & \\
\hline T1 & 42,9 & $61,6 \mathrm{ab}$ & 104,5 \\
T2 & 42,3 & $70,8 \mathrm{ab}$ & 113,0 \\
T3 & 42,7 & $66,6 \mathrm{ab}$ & 109,3 \\
T4 & 39,3 & $75,2 \mathrm{a}$ & 114,5 \\
T5 & 45,8 & $74,5 \mathrm{ab}$ & 120,2 \\
T6 & 47,2 & $56,7 \mathrm{~b}$ & 103,9 \\
T7 & 48,7 & $71,4 \mathrm{ab}$ & 120,2 \\
\hline F & $1,76^{\text {ns }}$ & $3,21^{*}$ & $2,41^{\text {ns }}$ \\
CV (\%) & 11,18 & 11,25 & 7,68 \\
\hline
\end{tabular}

(1)Médias seguidas pela mesma letra na coluna não diferem entre si pelo teste de Tukey, a 5\% de probabilidade. ${ }^{(2)} \mathrm{T} 1$, Brachiaria ruziziensis (B.r.) na entrelinha sem cobertura morta $(\mathrm{CM})$ na linha; T2, B.r. na entrelinha e CM na linha; T3, B.r. consorciada com amendoim forrageiro na entrelinha e CM na linha; T4, B.r. e estilosantes na entrelinha e CM na linha; T5, capim-marmelada na entrelinha e CM na linha; T6, amendoim forrageiro na entrelinha e CM na linha; T7, estilosantes


de probabilidade.

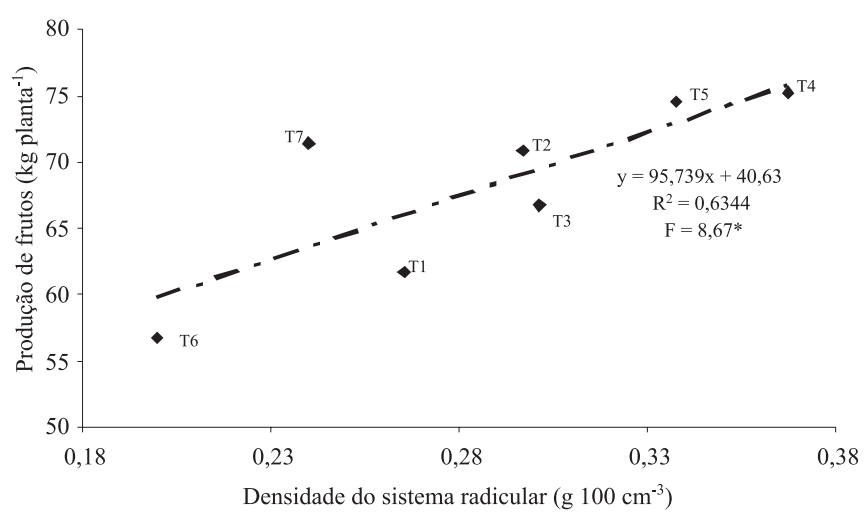

Figura 2. Produção de frutos de laranjeira 'Pêra', enxertada em limoeiro 'Cravo', decorrente da densidade de raízes fibrosas na camada de $0-10 \mathrm{~cm}$ de profundidade. *Significativo pelo teste $\mathrm{F}$, a $5 \%$ de probabilidade.

radicular e, conseqüentemente, a produção de frutos. As correlações observadas demonstram a importância das raízes situadas na camada superficial do solo, tanto para a nutrição quanto para a produção de frutos, reforçando recomendações de pesquisadores e técnicos no manejo conservacionista do solo.

\section{Conclusões}

1. Os sistemas de manejo utilizados não alteram as propriedades químicas do solo.

2. A cobertura morta de Brachiaria ruziziensis na quantidade em que foi distribuída não afeta a disponibilidade de $\mathrm{N}$ para as laranjeiras.

3. A densidade do sistema radicular nas camadas superficiais do solo não é afetada pelos sistemas de manejo do solo.

4. A absorção de $\mathrm{P}$ e a produção de frutos é aumentada pelo incremento da densidade do sistema radicular na camada superficial do solo.

\section{Agradecimentos}

À Branco Peres Citrus, pela concessão da área e apoio financeiro e operacional.

\section{Referências}

ALCÂNTRA, F.A. de; FURTINI NETO, A.E.; PAULA, M.B. de; MESQUITA, H.A. de; MUNIZ, J.A. Adubação verde na recuperação da fertilidade de um Latossolo Vermelho-Escuro degradado. Pesquisa Agropecuária Brasileira, v.35, p.277-288, 2000. 
CADISH, G.; SCHUNKE, R.M.; GILLER, K.E. Nitrogen cycling in a pure grass pasture and a grass-legume mixture on a red latosol in Brazil. Tropical Grasslands, v.28, p.43-52, 1994.

CARVALHO, J.E.B. de; SOUZA, L.S.; SOUZA, L.D.; CALDAS, R.C.; RAMOS, W.F.; COSTA NETO, A.O.; ARAÚJO, A.M.A.; LOPES, L.C.; SILVEIRA, J.R.S. Manejo do solo no controle integrado de plantas daninhas em citros. Revista Brasileira de Fruticultura, v.20, p.21-27, 1998.

CORÁ, J.E.; SILVA, G.O.; MARTINS FILHO, M.U. Manejo do solo sob citros. In: MATTOS JÚNIOR, D. de; NEGRI, J.D.; PIO, R.M.; POMPEU JÚNIOR, J. (Ed.). Citros. Campinas: Instituto Agronômico; Fundag, 2005. p.347-369.

DONIZETI CARLOS, J.A.; COSTA, J.A. da; COSTA, M.B. da. Adubação verde: do conceito à prática. Piracicaba: Esalq, 2006. 32p. (Série Produtor Rural, 30).

FABER, B.A.; DOWNER, A.J.; MENGE. J.A. Differential effects of mulch on citrus and avocado. Acta Horticulturae, v.557, p.303307, 2001.

FIDALSKI, J.; MARUR, C.J.; AULER, P.A.M.; TORMENA, C.A. Produção de laranja com plantas de cobertura permanente na entrelinha. Pesquisa Agropecuária Brasileira, v.41, p.927-935, 2006.

FIDALSKI, J.; STENZEL, N.M.C. Nutrição e produção de laranjeira 'Folha Murcha' em porta-enxertos e plantas de cobertura permanente na entrelinha. Ciência Rural, v.36, p.807-813, 2006.

GALLO, J.R.; RODRIGUEZ, O. Efeitos de algumas práticas de cultivo do solo, na nutrição mineral dos citros. Bragantia, v.19, p.345-360, 1960.

MALAVOLTA, E. ABC da análise de solo e folhas: amostragem, interpretação e sugestões de adubação. São Paulo: Ed. Agronômica Ceres, 1992. 124p.

MALAVOLTA, E. Elementos de nutrição mineral de plantas. São Paulo: Ed. Agronômica Ceres, 1980. 251p.

MARSCHNER, H. Functions of mineral nutrients: macronutrients. In: Mineral nutrition of higher plants. $2^{\text {nd }}$ ed. San Diego: Academic Press, 1995. p.229-312.

MATHEIS, H.A.M.; VICTORIA, R. Cover crops and natural vegetation mulch effect achieved by mechanical management with lateral rotary mower in weed population dynamics in citrus. Journal of Environmental Science and Health, Part B: Pesticides Food Contaminants and Agricultural Wastes, v.40, p.185-190, 2005.

MEDINA, C.L.; RENA, A.B.; SIQUEIRA, D.L.; MACHADO, E.C. Fisiologia dos citros. In: MATTOS JÚNIOR, D.; NEGRI, J.D.; Pio, R.M.; POMPEU JÚNIOR, J (Ed.). Citros. Campinas: Instituto Agronômico; Fundag, 2005. p.148-195.

MELARATO, M.S. A cobertura vegetal do solo na citricultura. In: SEMINÁRIO INTERNACIONAL DE CITROS - TRATOS CULTURAIS, 5.,1998, Bebedouro. Anais. Bebedouro: Fundação Cargill, 1998. p.203-221.

MENEGUCCI, J.L.P.; AMARAL, A.M. do; SOUZA, M. de. Alterações nas propriedades químicas do solo na camada subsuperficial após adubação verde com crotalária. Revista Brasileira de Fruticultura, v.17, p.7-12, 1995.

NEVES, C.S.V.J.; DECHEN, A.R. Sistemas de manejo de solo em pomar de tangerina Ponkan sobre limão 'Cravo' em Latossolo Roxo. Laranja, v.22, p.157-166, 2001.

PAVAN, M.A.; CARAMORI, P.H.; ANDROCIOLI FILHO, A.; SCHOLZ, M.F. Manejo da cobertura do solo para formação e produção de uma lavoura cafeeira. Influência na fertilidade do solo. Pesquisa Agropecuária Brasileira, v.21, p.187-192, 1986.

PERIN, A.; SANTOS, R.H.S.; URQUIAGA, S.; GUERRA, S.G.M.; CECON, P.R. Produção de fitomassa, acúmulo de nutrientes e fixação biológica de nitrogênio por adubos verdes em cultivo isolado e consorciado. Pesquisa Agropecuária Brasileira, v.39, p.35-40, 2004.

QUAGGIO, J.A.; MATTOS JÚNIOR, D.; CANTARELLA, H. Manejo da fertilidade do solo na citricultura. In: MATTOS JÚNIOR, D. de; NEGRI, J.D.; PIO, R.M.; POMPEU JÚNIOR, J. (Ed.). Citros. Campinas: Instituto Agronômico; Fundag, 2005. p.485-504.

RAGOZO, C.R.A.; LEONEL, S.; CROCCI, A.J. Adubação verde em pomar cítrico. Revista Brasileira de Fruticultura, v.28, p.69$72,2006$.

SILVA, J.A.A. da; VITTI, G.C.; STUCHI, E.S.; SEMPIONATO, O.R. Reciclagem e incorporação de nutrientes ao solo pelo cultivo intercalar de adubos verdes em pomar de laranjeira 'Pêra'. Revista Brasileira de Fruticultura, v.24, p.225-230, 2002. 